\title{
ANALISIS SEMIOTIK TERHADAP VCD PEMBELAJARAN "MENGGAMBAR KREATIF BERSAMA EINSTEIN DAN FABER-CASTELL SERI 1: PETUNJUK MENGGAMBAR KREATIF UNTUK ANAK-ANAK"
}

\author{
Elly Herliyani ${ }^{1}$, I Nyoman Rediasa ${ }^{2}$ \\ 1,2 Jurusan Pendidikan Seni Rupa, Fakultas Bahasa dan Seni \\ Universitas Pendidikan Ganesha \\ Singaraja, Indonesia \\ e-mail: ellyherliyani@gmail.com, polenk rediasa@yahoo.com
}

\begin{abstract}
Abstrak
VCD pembelajaran cara menggambar dan mewarnai menggunakan produk Faber-Castell perlu dikaji dengan ilmu semiotik, karena semiotik dapat membaca tanda apa yang kita lihat dan apa maksud penyampaian pesan. Penelitian menggunakan metode analisis tekstual dengan pendekatan semiotik, untuk membedakan unsur atau elemen tanda pada sebuah objek berdasarkan teori Roland Barthes dan teori Charles Sanders Peirce. Data dikumpulkan menggunakan metode observasi, wawancara, dan dokumentasi. Hasil analisis menunjukkan terdapat ikon, indeks, dan simbol yang merupakan tanda denotasi dari pesan yang disampaikan kepada audience, diteliti berdasarkan tanda verbal, tanda nonverbal dan tanda visual. Tanda konotasi meminjam citra positif Einstein, sehingga adanya mitos Einstein pintar menggambar karena produk Faber-Castell. Kode diperlukan untuk menyampaikan informasi Faber-Castell sebagai produsen peralatan menulis dan menggambar, serta Einstein sebagai artis profesional.
\end{abstract}

Kata kunci: Faber-Castell, menggambar, mewarnai, semiotika, VCD pembelajaran.

\begin{abstract}
An Instructional VCD of a Technique of Drawing and Colouring using a product of FaberCastell should be analysed based on semiotic science, since this science could read the sign that could be visibly seen and the meaning it could be expressed. This study was conducted based on a textual analysis with a semiotic approach, in order to distinguish between elements of signs in an object according to the concept of Roland Barthes and other concept of Charles Sanders Pierce. The data were collected by using observation, interview and documentation methods. The results of analysis indicated that there were found icons, indexes and symbols used as denotation marks of the message expressed to the audiences, studied based on the verbal, non verbal as well as visual signs. The connotation signs borrowed the Einstein positive image, so that there was a myth such as Einstein was very clever in drawing because of Faber-Castell products. Codes were needed in order to express information about Faber-Castell as a producer of wiring and drawing instrument, and Einstein as a professional artist.
\end{abstract}

Key-words: Faber-Castell, drawing, colouring, semiotics, instructional VCD.

\section{PENDAHULUAN}

Seni rupa sebagai ilmu yang memerlukan keahlian tersendiri untuk menciptakan karya didukung dengan media seni rupa, baik itu media cetak dan elektronik berkembang dengan sangat cepat dan berteknologi tinggi, bertujuan lebih praktis dalam hal penyampaian informasi sehingga lebih cepat untuk dipahami oleh audience.

$\begin{array}{rrrr}\text { Media } & \text { promosi } & \text { dibuat dan } \\ \text { dikembangkan } & \text { dari } & \text { perusahaan }\end{array}$ 
berdasarkan kebutuhan yang bisa ditawarkan, salah satunya adalah peralatan menggambar dan mewarnai dengan target konsumen anak-anak. Faber-Castell sebagai salah satu perusahaan yang mengerti kebutuhan perkembangan pembelajaran anak-anak, membuat media menggambar untuk mempromosikan program Playing and Learning atau lebih dikenal dengan istilah Red Range, yaitu rangkaian produk menggambar dan mewarnai ditujukan untuk anak-anak berusia 3 s.d 12 tahun. Program Playing and Learning bertujuan untuk mengembangkan kreasi menggambar anak-anak yang menyukai bermain sambil belajar.

Media menggambar untuk anak-anak dijual oleh Faber-Castell dengan melakukan teknik menyertakan hadiah (dinamakan premium) di beberapa produk kategori Playing and Learning. Produk dari FaberCastell seperti Connector Pen berhadiah premium VCD (Video Compact Disk). VCD pembelajaran menggambar produksi FaberCastell seri 1 ditujukan untuk penggunaan secara individu. Konsumen yang telah membeli produk Faber-Castell juga mempunyai VCD pembelajaran menggambar bersama Einstein Kristiansen, sehingga konsumen bisa berinteraksi belajar menggambar menggunakan produk FaberCastell. VCD juga merupakan media pembelajaran menggambar dan mewarnai, salah satu media Desain Komunikasi Visual (DKV) yang berhubungan dengan desain multimedia interaktif. Tinarbuko (2008: 2) menyatakan bahwa DKV adalah ilmu yang mempelajari konsep komunikasi dan ungkapan daya kreatif, yang diaplikasikan dalam pelbagai media komunikasi visual dengan mengolah elemen desain grafis terdiri dari gambar (ilustrasi), huruf, warna, komposisi, dan layout. Semuanya itu dilakukan guna menyampaikan pesan secara visual, audio, dan audio visual kepada target sasaran yang dituju.

DKV yang ada di VCD pembelajaran menggambar produksi Faber-Castell seri 1, membawakan pesan baik itu unsur komunikasi verbal, komunikasi nonverbal, dan komunikasi visual, juga berhubungan dengan tanda verbal, tanda nonverbal, dan tanda visual. Tanda-tanda tersebut dapat dikaji dengan ilmu semiotika bagaimana tanda itu dibuat, bagaimana maksud dari tanda itu, dan tujuan dari tanda tersebut.

Semiotika adalah ilmu yang mempelajari tentang tanda (sign), berfungsinya tanda, dan produksi makna (Tinarbuko, 2008: 12). Sehubungan dengan hal tersebut tanda-tanda berinteraksi dalam aktivitas kehidupan manusia berdasarkan dengan konvensi yang berlaku, sehingga manusia mudah memahami informasi yang ditangkap berdasarkan makna, yaitu petanda dan penanda. Manusia selalu dipenuhi oleh informasi yang disampaikan media dan dapat dipahami dengan ilmu semiotika.

Saussure (dikutip oleh Piliang, 2003: 258) menyatakan bahwa tanda adalah sebagai kesatuan yang tak dapat dipisahkan, yaitu bidang penanda (signifier) untuk menjelaskan bentuk atau ekspresi (bunyi atau tanda tertulis), serta bidang petanda (signified) untuk menjelaskan konsep atau makna."

VCD dapat diteliti melalui analisis semiotik berdasarkan jenis makna, tanda dan kode. Perusahaan Faber-Castell dalam mempromosikan produk mereka, menggunakan Einstein Kristiansen, sehingga mengasosiasikan Einstein sebagai seorang seniman sukses juga menggunakan produk Faber-Castell.

VCD mengandung tingkatan tanda, jenis tanda, dan jenis kode. Tingkatan tanda yaitu: denotasi dan konotasi berdasarkan teori Roland Barthes menemukan teori mengenai lapisan makna dari tanda, yaitu tingkat denotasi dan konotasi. Makna denotasi adalah makna paling nyata dari tanda. Makna konotasi adalah makna yang dihasilkan dari perasaan serta nilai-nilai dari kebudayaan.

Bartes (dikutip oleh Fiske, 2007: 121) juga melihat bekerjanya tanda pada pemaknaan tatanan kedua dari petanda 
yang disebut dengan mitos menyatakan bahwa mitos adalah cerita yang digunakan suatu kebudayaan untuk menjelaskan atau memahami beberapa aspek dari realitas atau alam. Mitos primitif berkenaan dengan hidup dan mati, manusia dan dewa, baik dan buruk.

Jenis tanda yaitu: ikon, indeks dan simbol berdasarkan teori Charles Sanders Peirce (dikutip oleh Sobur, 2006: 34) menyatakan bahwa tanda-tanda berkaitan dengan objek-objek yang menyerupainya, keberadaannya memiliki hubungan sebabakibat dengan tanda-tanda atau karena ikatan konvensional dengan tanda-tanda tersebut. la menggunakan istilah ikon untuk kesamaannya; indeks untuk hubungan sebab-akibat, menunjukkan, mewakilkan; simbo/ untuk asosiasi konvensional.

Jenis kode, yaitu: kode hermeneutika, kode semantik, kode simbolik, kode narasi dan kode kultural berdasarkan teori Roland Barthes. Uraian kode-kode tersebut dijelaskan Pradopo (dikutip oleh Tinarbuko, 2008: 18-19), yaitu: 1) Kode hermeneutika atau kode teka-teki berkisar pada harapan pembaca untuk mendapatkan "kebenaran" bagi pertanyaan yang muncul dalam teks. Kode teka-teki merupakan unsur struktur yang utama dalam narasi tradisional. Di dalam narasi ada suatu kesinambungan antara pemunculan suatu peristiwa teka-teki dan penyelesaiannya di dalam cerita. Siapakah mereka? Apa yang terjadi? Halangan apakah yang muncul? Bagaimanakah tujuannya? Jawaban yang satu menunda jawaban lain. 2) Kode semantik (semik) atau kode konotatif menawarkan banyak sisi. Dalam proses pembacaan, pembaca menyusun tema suatu teks. la melihat bahwa konotasi kata atau frase tertentu dalam teks dapat dikelompokkan dengan konotasi kata atau frase yang mirip. Jika kita melihat suatu kumpulan satuan konotasi, kita menemukan suatu tema di dalam cerita. Atau dengan kata lain kode semantik adalah tanda-tanda yang ditata sehingga memberikan suatu konotasi maskulin, feminin, kebangsaan, kesukuan, loyalitas. 3) Kode simbolik yaitu kode yang berkaitan dengan psikoanalisis, antithesis, kemenduaan, pertentangan dua unsur, skizofrenia. 4) Kode narasi atau kode proaretik dianggapnya sebagai perlengkapan utama teks yang dibaca orang. Artinya semua teks yang bersifat naratif. 5) Kode kultural atau kode gnomik merupakan acuan teks ke benda-benda yang sudah diketahui oleh budaya, seperti mitos, kebijaksanaan, pengetahuan, sejarah, moral, psikologi, sastra, seni, legenda.

Interpretasi sebuah VCD

pembelajaran menggambar produksi FaberCastell seri 1 , hanya membahas ihwal yang berkaitan dengan jenis makna, tanda dan kode. Maka berdasarkan latar belakang masalah di atas dapat dirumuskan yaitu: 1) Bagaimana tingkatan tanda, yaitu: denotasi dan konotasi berdasarkan teori Roland Barthes dan penerapannya pada VCD pembelajaran menggambar produksi FaberCastell seri 1? 2) Bagaimana jenis tanda, yaitu: ikon, indeks dan simbol berdasarkan teori Charles Sanders Peirce dan penerapannya pada VCD pembelajaran menggambar produksi Faber-Castell seri 1? 3) Bagaimana jenis-jenis kode, yaitu: kode hermeneutika, kode semantik, kode simbolik, kode narasi dan kode kultural berdasarkan teori Roland Barthes dan penerapannya pada VCD pembelajaran menggambar produksi Faber-Castell seri 1?

Analisis semiotik bertujuan untuk memahami VCD pembelajaran menggambar produksi Faber-Castell seri 1, dengan menggunakan teori Roland Barthes berdasarkan jenis makna denotasi dan konotasi, serta berdasarkan jenis kode hermeneutika, kode semantik, kode simbolik, kode narasi dan kode kultural; teori Charles Sanders Peirce berdasarkan jenis tanda ikon, indeks dan simbol.

Analisis semiotik mempunyai manfaat agar 1) Hasil pemikiran dapat disumbangkan bagi perkembangan ilmu semiotika dengan mengkaji jenis makna, tanda dan kode. 2) 
Wawasan menjadi bertambah melalui materi VCD pembelajaran menggambar produksi Faber-Castell seri 1. 3) Lembaga Penelitian Universitas Pendidikan Ganesha Singaraja semakin menambah ilmu pengetahuan mengenai analisis semiotik VCD pembelajaran menggambar produksi Faber-Castell seri 1. 4) PT. Faber-Castell International Indonesia mendapat hasil penelitian yang dijadikan pedoman membuat VCD pembelajaran menggambar selanjutnya. 5) Masyarakat khususnya anakanak dan orang tua, serta umumnya mahasiswa mendapat wawasan analisis semiotik terhadap VCD pembelajaran menggambar produksi Faber-Castell seri 1.

\section{METODE}

Analisis teks media dari VCD pembelajaran menggambar produksi FaberCastell seri 1 menggunakan metode analisis tekstual. Jane Stokes (2006: 57) menyatakan bahwa mempelajari teks dapat memperbaiki pemahaman kita mengenai kehidupan kultural - tentang makna berbagai hal - sementara makna adalah salah satu aspek paling penting dalam penggunaan media (media use).

Penelitian menggunakan metode analisis tekstual dengan pendekatan semiotik, dilakukan untuk mencari makna teks atau citra (image). Semiotika dapat berbahan sejumlah penafsiran terhadap makna dari VCD pembelajaran menggambar produksi Faber-Castell seri 1. Metode analisis tekstual yang digunakan berhubungan dengan penelitian kualitatif.

Maka dari itu penelitian ini menggunakan metode analisis tekstual dengan pendekatan semiotik, yaitu teori semiotika struktural mengkaji struktur gambar, sedangkan Peirce membantu dalam menjelaskan bagian yang ada dari semiotika struktural.

\section{HASIL DAN PEMBAHASAN}

Tingkatan Tanda Denotasi dan Konotasi, dengan hasil sebagai berikut: a. Tingkatan tanda denotasi yaitu makna yang sebenarnya pada keduapuluhtujuh sequence di VCD pembelajaran menggambar Faber-Castell seri 1, yaitu: 1) Aktor Einstein Kristiansen; dia adalah seorang aktor profesional, baik itu dalam bidang menggambar, melukis, desainer, dan penyiaran (broadcasting). Keahliannya digunakan untuk membawakan materi menggambar dengan menggunakan produk Faber-Castell. 2) Aktor dan artis pendukung; mereka tampil di sequence iklan FaberCastell 1 s.d 4, terdiri dari anak laki-laki dan anak perempuan, guru, siswa-siswi, pegawai kantor, penjual peralatan tulis dan buku, serta reporter Faber-Castell. 3) Produk-produk Faber-Castell; Einstein menggambar dengan produk Faber-Castell yaitu pensil, Marker, Watercolour Pencils, Jumbo Colour Pencils, Classic Colour Pencils, Connector Pen, Wax Crayon, Medium Black Marker, dan Poster Art Pen. 4) Iklan-iklan Faber-Castell; yang terdiri dari iklan undian berhadiah berisi informasi iklan undian berhadiah, iklan Faber-Castell 1 s.d 4 memperlihatkan kecanggihan produkproduk Faber-Castell. 5) Latar belakang syuting; diperlihatkan berbagai latar belakang syuting yaitu, di sekolah, di dalam kelas, kantor, toko buku, dalam rumah, dan dalam rumah animasi dengan tampilan latar belakang peralatan mewarnai Faber-Castell. 6) DKV terdiri dari (a) teknik video ada framing, camera angle, pergerakan kamera, istilah bahasa film; (b) layout; (c) unsurunsur DKV pada layout; (d) prinsip-prinsip desain pada layout; (e) prinsip-prinsip desain pada tampilan video; (f) huruf; (g) logo. 7) Ikon, indeks, dan simbol, juga termasuk di dalam makna denotasi karena berhubungan dengan makna sebenarnya.

b. Tingkatan tanda konotasi yaitu makna yang tidak sebenarnya dengan perasaan pada keduapuluhtujuh sequence di VCD pembelajaran menggambar Faber-Castell seri 1, yaitu: 1) Einstein Kristiansen sebagai orang "penting" atau sebagai tanda utama, karena Einstein memberikan materi pembelajaran menggambar. 2) Sifat 
Einstein yang selalu tersenyum karena dia bisa berjumpa dengan audience yang telah menggunakan VCD produksi Faber-Castell. 3) Einstein tidak lupa untuk selalu memperlihatkan produk Faber-Castell yang ada di tangannya, karena itu adalah barang "penting" bagi Einstein untuk menyelesaikan karyanya menjadi lebih indah. 4) Baju Einstein yang bernuansa nonformal, sehingga hubungan dengan audience "lebih dekat" karena Einstein terlihat "santai". 5) Faber-Castell sebagai perusahaan besar dan mempunyai "kekuatan lebih besar" untuk membuat pensil raksasa di dunia, dan "mampu" mengajak Einstein seniman profesional untuk bekerja sama mempromosikan produk Faber-Castell. 6) Pensil Faber-Castell menjadi cikal bakal perkembangan peradaban manusia yang dihasilkan dari ide manusia dalam membangun masa depan yang lebih baik. 7) Hasil gambar yang bisa hidup, karena menggunakan produk Faber-Castell yang mendukung imajinasi manusia di semua usia. 8) Faber-Castell yang menyelenggarakan undian berhadiah untuk mencurahkan perhatiannya kepada audience yang telah menggunakan produkproduknya. 9) Karya Einstein yang sudah diwarnai dengan produk Faber-Castell bisa hidup dan ceria karena sudah digambar dengan Einstein dan Faber-Castell. 10) Guru yang membantu siswa dengan peralatan ujian Faber-Castell, membina hubungan yang baik antara guru dan siswa. 11) Siswa dapat mengerjakan soal ujian di lembar jawaban ujian dengan baik dan bersih bersama peralatan ujian FaberCastell, sehingga para siswa senang dengan Faber-Castell. 12) Paket ujian Faber-Castell dengan premium VCD bank soal ujian membantu para pelajar untuk lulus ujian bersama Faber-Castell.

Faber-Castell membantu keuntungan perusahaan dalam pengadaan peralatan tulis-menulis, karena lebih terjangkau dan tahan lama, membantu penjual peralatan tulis-menulis karena menjual Faber-Castell lebih gampang, paling lengkap, dan lebih laris. 14) Faber-Castell menjadi sahabat setia segala usia, yang dapat membantu dan memperlancar kehidupan manusia sehari-hari. Selain manusia, juga ada kehidupan para hewan dan lingkungan, karena Faber-Castell peduli dengan kelestarian hutan dan keamanan lingkungan dari limbah yang berbahaya. 15) Animasi dari iklan-iklan menambah kedinamisan pada tampilan, dan dapat menarik perhatian audience. Makna konotasi juga menimbulkan mitos di beberapa sequence, yaitu: 1) Sejarah Faber-Castell; Mitos Einstein dan Faber-Castell, yaitu mitos Einstein seorang kartunis profesional, serta mitos Faber-Castell dengan produk yang paling terdepan dalam inovasi. 2) Menggambar 1, 2, 3, 4, 5; Mitos anak-anak agar mempunyai pikiran dan imajinasi yang indah dari kehidupan para hewan. 3) Menggambar 6; Mitos gading gajah yang diyakini memiliki khasiat sebagai jimat penangkal marabahaya. 4) Iklan Produk Faber-Castell 1; Mitos kasih sayang yang bisa diwujudkan dengan pembelian barangbarang untuk "menggantikan" perhatian orang tuanya yang sibuk bekerja. 5) Iklan Produk Faber-Castell 2; Mitos guru yang terkenal galak dan perkataan guru yang tidak boleh dilanggar. Tetapi dengan perkembangan jaman, kegalakan guru diganti dengan keseriusan, dan ketegasan, serta kasih sayangnya dalam mendidik siswa. 6) Iklan Produk Faber-Castell 3; Mitos keberhasilan benda-benda keberuntungan dari produk Faber-Castell, terutama pensil dan penghapusnya untuk membantu menjawab soal ujian.

Jenis Tanda Ikon, Indeks, dan Simbol, dengan hasil sebagai berikut: 1) Ikon, indeks, dan simbol berhubungan dengan makna denotasi, karena apa yang tampak di VCD pembelajaran. Sebelum dijabarkan ikon, indeks, dan simbol, maka pertama kali dilihat tampilan video, komunikasi visual dari shot karya Einstein, komunikasi visual dari shot layout, dan DKV. 2) Ikon dilihat dari tampilan di masing-masing sequence, di antaranya ada ikon: Einstein Krististiansen, 
animasi Einstein Kristiansen, ikon guru, ikon siswa, ikon pegawai kantor, ikon penjual peralatan tulis-menulis, ikon reporter, ikon teks, ikon warna, ikon gambar dan ikon latar belakang. 3) Indeks dilihat dari gesture Einstein sedang tersenyum, merupakan indeks bahwa ada sesuatu hal atau kejadian yang membuatnya tersenyum. 4) Simbol dilihat dari simbol Einstein Kristiansen, berbentuk ikon ilustrasi kepala tanpa rambut dan garis-garis memancar di sekeliling kepalanya, serta adanya teks Einstein. Simbol tandatangan Einstein merupakan identitas Einstein. Logo Faber-Castell yang berbentuk siluet prajurit sedang bertarung, dengan teks Faber-Castell. 5) Simbol pada teks dominan berbahasa Indonesia, dan ada juga teks berbahasa Thailand.

Jenis-jenis Kode, dengan hasil sebagai berikut: 1) Kode hermeneutika mengandung makna provokatif mengajak audience untuk ikut serta "hanyut" dalam emosi tampilan desain. 2) Kode semantik (semik) loyalitas dari Einstein Kristiansen menggunakan produk-produk Faber-Castell. 3) Kode simbolik terlihat pada pertentangan dua unsur dari sifat Einstein yang kekanakkanakan, tetapi sebenarnya dia bisa serius dan seorang seniman yang handal. 4) Kode narasi atau kode proaretik didapat dari cerita atau narasi dari perihal sequence urutan pembelajaran menggambar. 5) Kode kultural atau kode gnomik ada di aspek pengetahuan Einstein dalam memberikan materi pembelajaran menggambar bersama produk Faber-Castell.

Deskripsi dan analisis data VCD pembelajaran menggambar produksi FaberCastell Seri 1 ada 27 sequence, kemudian dibahas dengan menyatukan tampilan sequence yang sama, dan akhirnya menjadi 16 sequence bertujuan untuk mempersingkat penjelasan.

Bahan-bahan pokok analisis dilakukan dengan terlebih dahulu membuat tabel untuk menampilkan, di antaranya adalah: durasi; komunikasi verbal dari narator; komunikasi non verbal dari tulisan maupun gerakan tangan yang menjadi gesture dan body language; komunikasi visual dari shot layout dan dari shot karya Einstein Kristiansen, jika video memperlihatkan layout maupun karyanya.

Dari tabel tersebut, maka dipilah menjadi jenis tanda ikon, indeks, dan simbol. Lalu dicari makna denotasi dan makna konotasi, serta mitos jika ada. Setelah itu dicari kode-kode di antaranya adalah kode hermeneutika, kode semantik (semik), kode simbolik, kode narasi atau kode proaretik, dan kode kultural atau kode gnomik.

Perlu diketahui bahwa makna denotasi itu adalah makna yang tampak, maka DKV juga adalah makna denotasi. Maka dari itu untuk mempermudah memilah ikon, indeks, dan simbol, pertama kali dilihat dari Desain Komunikasi Visual yang memuat tampilan video, layout, maupun karya Einstein yang dibuat khusus di bagian DKV. Setelah itu, ada bagian denotasi yang dibuat untuk ikon, indeks, dan simbol.

Makna denotasi yang sudah didapat, kemudian makna konotasi dilakukan untuk mencari makna dari penanda dikaitkan dengan aspek perasaan, emosi atau keyakinan pada tampilan video, layout maupun karya Einstein. Makna konotasi juga menimbulkan mitos di beberapa sequence.

Makna konotasi dari ekspresi budaya menghasilkan ideologi melalui kode dalam bentuk penanda penting, yaitu kode hermeneutika, kode semantik (semik), kode simbolik, kode narasi atau kode proaretik, dan kode kultural atau kode gnomik. Berikut adalah penjelasan ke-16 sequence.

Pembukaan: Sampul, di sequence pertama ada bagian pembuka VCD pembelajaran menggambar. Konotasinya Einstein sebagai orang "penting". Tidak ada mitos. Kode utamanya narasi (proairetik).

Intro panjang, di sequence bagian kedua, kesembilan, keenambelas, dan keduapuluhtiga, ada animasi Einstein dan logo Einstein. Konotasinya animasi Einstein sebagai orang "penting". Tidak ada mitos. Kode utamanya hermeneutika, dan narasi. 
Sejarah Faber-Castell, di sequence ketiga, ada Faber-Castell dan Einstein Kristiansen. Konotasinya Einstein pintar menggambar dan berimajinasi karena produk Faber-Castell yang sudah berusia 240 tahun. Mitos Einstein dan Faber-Castell. Kode utamanya hermeneutika, dan kultural di aspek sejarah Faber-Castell.

Jingle Faber-Castell, yaitu: di sequence bagian keempat, kesebelas, dan kedelapanbelas, ada Jingle Faber-Castell. Konotasinya Faber-Castell bisa menghidupkan imajinasi anak-anak. Tidak ada mitos. Kode utamanya narasi, kode kultural di aspek bawah sadar dari imajinasi.

Intro pendek, yaitu di sequence bagian kelima, keduabelas, dan kesembilanbelas, ada animasi Einstein dan logo Einstein. Konotasinya Einstein sebagai orang "penting". Tidak ada mitos. Kode utamanya kultural di aspek moral.

Iklan undian berhadiah, yaitu di sequence bagian keenam, ketigabelas, dan keduapuluh, ada hadiah dari Faber-Castell. Konotasinya produk Faber-Castell sebagai barang "penting". Tidak ada mitos. Kode utamanya semantik, dan kultural di aspek kebijaksanaan.

Menggambar 1 di sequence ketujuh, ada gambar hewan kumbang, burung hantu, harimau, dan sapi. Konotasinya FaberCastell membantu Einstein menemukan ide untuk menggambar. Mitosnya adalah mitos anak-anak. Kode utamanya hermeneutika.

Menggambar 2 di Sequence kesepuluh, ada gambar tiga ekor sapi yang tampil di dalam kotak televisi. Konotasinya adalah tiga ekor sapi yang ingin terkenal. Mitosnya adalah mitos anak-anak. Kode utamanya kode kultural di aspek psikologi, aspek mitos, aspek pengetahuan, dan aspek seni.

Menggambar 3 di sequence keempatbelas, ada gambar seekor dinosaurus, serta hutan sebagai latar belakang. Konotasinya adalah seekor dinosaurus berbadan besar takut dengan seekor kumbang bertubuh sangat kecil.
Mitosnya adalah mitos anak-anak. Kode utamanya hermeneutika dan narasi.

Menggambar 4 di sequence ketujuhbelas, ada gambar seekor jerapah, sapi, gajah, ular, ikan, dan kumbang. Konotasinya adalah sekumpulan gambar hewan yang gembira dan cantik, karena Connector Pen dan Wax Crayon dari FaberCastell. Mitosnya adalah mitos anak-anak. Kode utamanya adalah hermeneutika, dan kultural di aspek mitos, aspek pengetahuan dan aspek seni.

Menggambar 5 di sequence keduapuluhsatu, ada gambar troll berkepala tiga sedang berada di hutan dan sinar bulan sebagai latar belakang. Konotasinya troll berkepala tiga berbadan besar mempunyai kekuatan besar dan berkuasa, sedangkan Einstein berbadan kecil tidak berdaya dan lemah. Mitosnya adalah mitos anak-anak. Kode utamanya hermeneutika dan simbolik.

Menggambar 6 di sequence keduapuluhempat, ada gajah di hutan Negara Srilangka; gambar seekor gajah sedang melompat, dan Einstein duduk di atas badannya sambil membawa kertas dan pensil Faber-Castell. Konotasinya gambar gajah senang bermain dengan Einstein bersama Faber-Castell. Mitosnya adalah mitos gading gajah. Kode utamanya simbolik, narasi (proairetik), kultural di aspek mitos, aspek kebijaksanaan, aspek pengetahuan, dan aspek seni.

Iklan produk Faber-Castell 1, yaitu di sequence bagian kedelapan, kelimabelas, dan keduapuluhdua. Konotasinya persaingan daya imajinasi untuk menjadi yang terbaik. Mitosnya adalah mitos kasih sayang. Kode utamanya semantik, kultural di aspek moral dan aspek kebijaksanaan.

Iklan produk Faber-Castell 2 di sequence keduapuluhlima. Konotasinya adalah produk Faber-Castell membuat lembar jawaban ujian tetap rapi dan bersih, sehingga membuat siswa lulus ujian. Mitosnya adalah mitos guru. Kode utamanya hermeneutika, narasi, kultural di aspek kebijaksanaan, dan aspek moral. 
Iklan produk Faber-Castell 3 di sequence keduapuluhenam. Konotasinya adalah produk Faber-Castell berkualitas dan berteknologi tinggi sanggup untuk dibeli oleh siswa-siswi SMA, dan membantu siswa untuk lulus ujian. Produk Faber-Castell membantu perkembangan pekerjaan di kantor, dan membantu keuntungan penjualan di toko. Mitosnya adalah mitos keberhasilan benda-benda keberuntungan dari produk Faber-Castell. Kode utamanya hermeneutika, narasi, kultural di aspek moral.

Penutup: iklan produk FaberCastell 4 di sequence keduapuluhtujuh. Konotasinya adalah tampilan animasi flash dan bodycopy atau bodytext bergerak lambat, mengkonotasikan sebagai makna yang paling penting. Diharapkan bodycopy dapat membujuk dan memprovokasi pembaca untuk membeli produk yang diiklankan. Tidak ada mitos. Kode utamanya hermeneutika, kultural di aspek pengetahuan dan mitos.

VCD pembelajaran menggambar Faber-Castell Seri 1, terdapat pola yang tetap, dan prinsip berpikir dari Einstein dan Faber-Castell untuk memberikan fakta yang sebenarnya. Pola terdiri dari: 1) Pola gambar hewan dari karya Einstein yang menarik, lucu dan sederhana sangat mudah untuk diterapkan oleh anak-anak. 2) Pola narasi dengan gaya bicara Einstein telah diisi dengan suara berbahasa Indonesia yang sederhana.

3) Pola gesture Einstein melalui tingkah-lakunya sesuai dengan jiwa anak-anak yang ceria dan bersemangat. Pola gesture dari aktor anak laki-laki dan anak perempuan sedang menggambar dengan Faber-Castell. Pola gesture dari aktor dan artis di sekolah, kantor, dan penjual buku peralatan menulis. 4) Pola menarik perhatian audience melalui cara Einstein mencirikan jati dirinya dengan kaos bergambar khasnya dan bersifat non-formal, Einstein yang meninggalkan tandatangan pada karyanya. Pola menarik perhatian audience dari FaberCastell melalui sajian iklan yang menarik dengan tampilan animasi, produk-produk Faber-Castell, serta hasil karya Einstein yang menggunakan produk Faber-Castell.

Prinsip terdiri dari: 1) Prinsip kejelasan gambar dari keenam materi pembelajaran menggambar yang dibawakan oleh Einstein Kristiansen menggunakan produk Faber-Castell, yaitu: a) materi pembelajaran menggambar hewan kumbang, burung hantu, harimau, dan sapi. b) materi pembelajaran menggambar tiga ekor hewan sapi yang tampil di dalam kotak televisi. c) materi pembelajaran menggambar seekor hewan dinosaurus, dan serangga, serta hutan sebagai latar belakang. d) materi pembelajaran menggambar seekor hewan jerapah, sapi, gajah, ular, ikan, dan kumbang. e) materi pembelajaran menggambar troll berkepala tiga sedang berada di hutan dan sinar bulan sebagai latar belakang. f) materi pembelajaran menggambar seekor hewan gajah sedang melompat, dan Einstein duduk di atas badannya sambil membawa kertas dan pensil Faber-Castell. 2) Prinsip kejenakaan diselingi dengan Intro Panjang, yang berisi animasi Einstein yang dibawa terbang oleh angin topan. Kejenakaan Einstein ketika dibawa terbang dan berubah menjadi animasi figur anak-anak, serta tujuan angin topan membawa Einstein ke suatu rumah di pulau tengah lautan. Prinsip kejenakaan lainnya adalah Einstein memberikan materi menggambar 1 sampai 6 , dia menggambar hewan yang lucu dan menggemaskan. Einstein ketika memberikan materi menggambar 3, Einstein membuat sketsa besar secara cepat tanpa melihat, kemudian dia melanjutkan sketsanya menjadi gambar dinosaurus. Einstein ketika memberikan materi menggambar 5, Einstein juga tidak malu untuk memeragakan gesture ilustratif yang menggambarkan gerak tubuh troll yang mirip dengan gorila. Einstein juga jenaka bersama gajah yang dinaikinya sambil berjalan-jalan di hutan, di materi menggambar 6. 3) Prinsip kekanakan menggunakan ikon Einstein Kristiansen merepresentasikan 
unsur-unsur lain, yaitu seorang yang humoris indeks dari tanda wajah (gesture) dan body language. Gesture Einstein sedang tersenyum dan tertawa menikmati kesehariannya sebagai juru gambar. Body language Einstein bertingkah laku enerjik seperti sikap kekanak-kanakan dan memberikan semangat kreativitas kepada audience. 4) Prinsip identitas dari Einstein ketika selesai berkarya, selalu menandatangani karyanya, sebagai simbol bahwa karya tersebut adalah buatan dia sendiri. Karyanya yang diselesaikan dengan perpaduan antara imajinasi Einstein dan peralatan menggambar Faber-Castell, mengasosiasikan Einstein menyukai menggambar dengan Faber-Castell. Hal ini merupakan strategi Faber-Castell melalui daya tarik dari citra Einstein sebagai juru gambar profesional menggunakan produk Faber-Castell. Masyarakat yang melihat hal tersebut, berpikiran bahwa ada nilai lebih dari produk Faber-Castell. Einstein juga menggunakan kaos yang berciri khasnya, yaitu kaos bergambar karyanya, menggunakan celana pendek $7 / 8$, bersepatu dan bertas pinggang.

5) Prinsip

kedisiplinan dari Einstein ketika berkarya, selalu mengambil peralatan menggambar Faber-Castell yang diletakkan di papan menggambar, serta tidak lupa dia menaruh kembali ke tempatnya semula. Hal ini mencitrakan dirinya berdisiplin dalam hal pemeliharaan peralatan menggambarnya. Di manapun Einstein berada, dia selalu berdiplin untuk menutup Connector Pen dengan tutupnya, maupun mengembalikan peralatan menggambar ke kemasan masingmasing. Audience yang melihat kedisiplinan Einstein bisa ditiru oleh mereka, serta citra positif Einstein menjadi bertambah karena tanggung jawab dari kedisiplinannya. 6) Prinsip pengulangan dari gerakan repetisi yang sama pada saat Einstein melihat hasil rekamannya ada di kotak televisi dan pergi meninggalkan lokasi. Ada di sequence ketujuh, yaitu menggambar 1 . Serta gerakan repetisi yang sama juga pada saat Einstein melihat hasil rekamannya dengan seksama.
Ada di sequence keduapuluhsatu, yaitu menggambar 5 terletak di akhir scene; sequence keduapuluhempat, yaitu menggambar 6 terletak di awal scene. 7) Prinsip fleksibilitas dari kertas gambar yang digunakan Einstein Kristiansen diletakkan di papan gambar dengan kertas yang besar, serta peralatan menggambar yang diletakkan di papan gambar. Tinggi papan disesuaikan dengan jangkauan tangan Einstein. Kertas gambar yang digunakan Einstein Kristiansen ketika menggambar di atas punggung gajah, Einstein menggunakan kover buku gambarnya sebagai alas untuk menggambar, sehingga dia bisa menggambar dengan baik. 8) Prinsip bentuk dari a) materi menggambar karya Einstein dominan terletak di tengah, dengan membuat gambar hewan berkesan dua dimensi, berbidang di kertas gambar warna putih. Warna gambar dominan cerah, seperti warna primer, sekunder, dan tertier. Karya Einstein diselesaikan dengan menggunakan produk Faber-Castell, dan langsung ditandatangani sebagai simbol logo Einstein Kristiansen. a) Einstein dalam melakukan peran sebagai penanda utama alur cerita, juga didukung dengan DKV, yang terdiri dari teknik video; layout; unsur-unsur Desain Komunikasi Visual pada layout; prinsipprinsip desain pada layout; prinsip-prinsip desain pada tampilan video; huruf; dan logo. c) Teknik video menggunakan framing; camera angle; pergerakan kamera; istilah bahasa film. Framing yang sudah digunakan adalah long shot, middle close up, very long shot, extreme long shot, close up, big close up, medium long shot, medium shot, extreme close up. Camera Angle yang sudah digunakan adalah eye level, one shot, high angle, bird eye view, group shot, over shoulder, top angle, frog eye level, two shot, artificial shot, back light shot, walking, low angle. Pergerakan kamera yang sudah digunakan adalah track in, pan left, pan right, tilt down, following, crane, tilt up, track out. Istilah bahasa film yang sudah digunakan adalah dissolve, wipe animasi 
kotak, zoom out, zoom in, walk out, walk in, fade out, wipe garis diagonal, efek huruf diketik. d) Prinsip bentuk dari beberapa sequence yang ada iklan menggunakan format dan teknik, di antaranya adalah sequence dari Sejarah Faber-Castell, Iklan Undian Berhadiah, dan Iklan Produk FaberCastell 1 s.d. 4. Format dan teknik yang digunakan sebagai berikut.

Sejarah Faber-Castell menggunakan 1) format informasi produk. Produk FaberCastell dijadikan pusat perhatian bagaimana cara memproduksi di pabrik Faber-Castell, dan keunggulannya ditonjolkan dalam sejarah Faber-Castell yang telah berproduksi selama \pm 250 tahun. 2) Format citra produk. Pabrik di Malaysia membuat pensil Faber-Castell berukuran raksasa, yang membuat citra pensil Faber-Castell adalah menguasai seluruh pensil-pensil merek lain di dunia. 3) Format personalisasi. Produk Faber-Castell telah mempengaruhi perkembangan peradaban kehidupan manusia, hingga sampai masa kini.

Format gaya hidup. Pensil Faber-Castell pernah dibuat untuk fashion gaya hidup modern. 5) Teknik dukungan (endorsement) dari Einstein Kristiansen yang sangat menyukai dan membuat imajinasinya berkembang karena produk Faber-Castell. 6) Teknik ahli, yang bekerjasama dengan para ahli pembuat mesin canggih untuk memproduksi dan mendukung inovasi Faber-Castell di pabrik.

\section{Iklan}

Undian

Berhadiah, menggunakan: format gaya hidup. Produk dari undian berhadiah, diasosiasikan dengan gaya hidup perkotaan, dengan undian berhadiah mobil, motor, meja belajar, sepeda, dan produk Faber-Castell.

Iklan Produk Faber-Castell 1, menggunakan: format informasi produk dari anak laki-laki dan anak perempuan sedang menggambar dengan produk Faber-Castell. Keunggulan dari pensil yang bisa berubah menjadi efek cat air, serta contoh cara menggunakannya.

Iklan Produk Faber-Castell 2, menggunakan: 1) Format informasi produk.
Produk Faber-Castell yang muncul di iklan ini adalah pensil dan penghapus untuk ujian. Produk dijadikan pusat perhatian, dan keunggulan ditonjolkan dengan dibandingkan produk merek lain yang kalah melawan kecanggihan produk Faber-Castell. 2) Format personalisasi. Produk FaberCastell membangun hubungan langsung antara produk dengan personalitas guru dan siswa. Produk dijadikan partner intim yang menemani siswa untuk menjawab lembar jawaban ujian, serta guru untuk menunjang pekerjaannya. Maka dari itu hubungan antara produk dan manusia saling mendukung satu sama lainnya.

Iklan Produk Faber-Castell 3, menggunakan: 1) Format informasi produk. Pertanyaan reporter "Mengapa pakai FaberCastell?" adalah salah satu pusat perhatian, menuju ke jawaban para aktor dan artis yang menyebutkan kesaksian masingmasing dengan kecanggihan serta kelebihan menggunakan produk FaberCastell. 2) Format personalisasi; aktor dan artis yang menggunakan produk FaberCastell, mempunyai hubungan yang saling menguntungkan, serta ketergantungan karena produk Faber-Castell telah menambah kebaikan dalam hidup mereka masing-masing. 3) Teknik dukungan (endorsement) dari kesaksian aktor dan artis yang memberitahu audience betapa menakjubkannya produk Faber-Castell. 4) Teknik nostalgia untuk menonjolkan perasaan dari aktor yang mengatakan "Waktu sekolah, saya pakai pensil FaberCastell." dilanjutkan dengan, "Untuk kantor, saya tetap menggunakan Faber-Castell". 5) Teknik "pujian pengguna" yang menyanjung konsumen audience, narator yang mengatakan,"Faber-Castell, Sahabat Setia Segala Usia". Audience yang mendengar kalimat ini terpengaruh pikirannya dengan keawetan dan kecanggihan produk FaberCastell.

Iklan Produk Faber-Castell 4, menggunakan: format personalisasi. Produk VCD pembelajaran menggambar FaberCastell Seri 2 meneruskan hubungan 
langsung antara produk Faber-Castell dengan personalitas audience yang telah membeli paket kemasan berhadiah premium VCD Seri 2. Akibatnya tambahan ilmu untuk audience berkembang, serta mengetahui kegunaan dari produk-produk Faber-Castell di VCD Seri 2 tersebut.

Fakta yang dibuat VCD Pembelajaran Menggambar Faber-Castell Seri 1 dari Jenis Tanda, Makna dan Kode, ada di Einstein Kristiansen, Faber-Castell, dan audience.

Einstein Kristiansen perlu dipahami audience yang baru mengenalnya. Einstein yang berulang-ulang hadir dan dukungan dari suara narator agar ikon baru diciptakan dalam pikiran audience, bahwa Einstein Kristiansen seorang juru gambar bekerjasama dengan Faber-Castell untuk membuat VCD pembelajaran menggambar Seri 1. Tanda-tanda Einstein Kristiansen sebagai publik figur untuk anak-anak direpresentasikan melalui ikon dirinya sendiri maupun gambar kartun. Indeks dari tanda wajah (gesture) dan body language. Indeks dari pakaian dan tas pinggang, simbol dari gambar yang diletakkan di belakang kaosnya, logo, serta tandatangannya. Einstein merepresentasikan jiwa anak-anak pada dirinya, sanggup mengangkat citra dirinya sebagai seniman yang mencintai anak-anak. Anak-anak yang sudah atau baru mengenal Einstein Kristiansen, dapat membangkitkan animo mereka menjadi seperti Einstein Kristiansen, seorang juru gambar profesional. Animo ini bertambah kuat, jika anak-anak sudah mengkoleksi VCD pembelajaran menggambar Faber-Castell Seri 1-4 bekerjasama dengan Einstein Kristiansen.

Faber-Castell meminjam citra positif Einstein Kristiansen untuk bekerjasama dengan perusahaan besar Faber-Castell dalam hal promosi produk kategori Red Range kelompok Playing and Learning, bersama-sama dengan relasi saling menguntungkan. Nama Einstein Kristiansen bertambah terkenal sebagai public figure, nama perusahaan Faber-Castell bertambah terkenal di lingkungan pendidikan dan umum. Faber-Castell juga bekerjasama dengan para aktor dan artis yang mendukung produk Faber-Castell di iklaniklannya, sehingga hal ini menambah keyakinan audience agar lebih mantap dan percaya dengan kecanggihan produk FaberCastell.

Audience yang sudah menonton VCD pembelajaran menggambar FaberCastell Seri 1 terpengaruh terhadap ikon Einstein Kristiansen yang baru, bahwa Einstein Kristiansen pintar menggambar karena menggunakan produk Faber-Castell kategori Red Range kelompok Playing and Learning. Maka dari itu mitos yang berkembang adalah audience pun menggunakan produk Faber-Castell agar pintar menggambar, nantinya audience bisa terkenal khususnya di lingkungan anakanak, dan umumnya di lingkungan masyarakat seperti Einstein Kristiansen.

\section{SIMPULAN DAN SARAN Simpulan}

Jenis makna denotasi adalah makna yang sebenarnya, yaitu apa yang kita lihat dalam VCD pembelajaran menggambar Faber-Castell Seri 1. Komunikasi berupa pesan dari makna denotasi pada VCD digunakan untuk mendeskripsikan tandatanda visual, tanda nonverbal, tanda verbal secara DKV dan ikon, indeks, serta simbol. Tanda verbal dari penjelasan narator, tanda nonverbal dari tulisan dan gerakan tangan, tanda visual dari gesture dan body language Einstein, aktor dan artis pendukung iklan Faber-Castell. Hasilnya adalah bahwa tanda visual penting untuk dilakukan Einstein yang dapat memberikan petunjuk kepada audience dengan pesan dan saran yang menarik, mengkonotasikan bahwa apa yang dilakukan Einstein Kristiansen adalah benar, bersemangat, kegembiraan Einstein disebabkan oleh produk Faber-Castell.

Jenis makna konotasi merujuk kepada makna-makna dan bagaimana tanda bekerja secara konotasi berlaku dalam kebudayaan dan diterima dalam kehidupan 
masyarakat. Ada makna yang direpresentasikan sedemikian rupa sehingga berpendapat hal tersebut adalah "wajar" dan "dibenarkan", yaitu mitos terhadap produk Faber-Castell yang mempunyai citra bahwa produk tersebut dapat meningkatkan imajinasi, kreativitas, kelulusan ujian, keuntungan, dan keberhasilan audience.

Jenis tanda ikon, indeks, dan simbol dengan hasil bahwa VCD pembelajaran merupakan karya DKV yang dijadikan objek penelitian memuat tanda ikon, indeks dan simbol. Ikon adalah sesuatu yang berhubungan dengan apa yang kita lihat di VCD, dari Einstein Kristiansen, aktor dan artis pendukung iklan Faber-Castell, lokasi syuting, karya Einstein. Indeks merupakan sesuatu yang menunjukkan, mewakilkan, dan sebabakibat di VCD, yaitu dari gesture dan body language Einstein sebagai penanda utama, serta narator yang menjelaskan materi pembelajaran menggambar. Simbol dari makna karya Einstein, makna layout, makna gerakan Einstein, makna gerakan aktor dan artis pendukung iklan Faber-Castell, serta makna logo Faber-Castell, maupun logo Einstein Kristiansen.

Jenis kode hermeneutika, semantik, simbolik, narasi, kultural, dengan hasil bahwa terdapat pelbagai makna di VCD tersebut sesuai dengan kode yang berkembang di kehidupan bermasyarakat, dan kode diperlukan untuk membaca informasi yang disampaikan melalui VCD tersebut. 1) Kode hermeneutika dominan untuk mengajak audience mendengarkan petunjuk teka-teki dari pertanyaan, dan berakhir dengan jawaban, sehingga setelah mengikuti alur cerita, baru terlihat karya Einstein yang sudah jadi. 2) Kode semantik dominan kepada konotasi loyalitas dari Einstein Kristiansen untuk menggunakan produk Faber-Castell. Konotasi loyalitas dari Faber-Castell berpengalaman untuk meningkatkan kualitas produk. Konotasi loyalitas dari audience yang telah menggunakan produk Faber-Castell. 3) Kode simbolik dominan pada pertentangan dua unsur dari sifat Einstein Kristiansen yang kekanak-kanakan, tetapi sebenarnya dia seorang serius, dan jenius, serta seniman yang handal.

Kode narasi terdapat pada alur cerita masing-masing sequence sehingga terbentuk menjadi VCD pembelajaran menggambar bersama Einstein dan FaberCastell Seri 1. 5) Kode kultural dominan di aspek pengetahuan dan aspek kebijaksanaan Einstein dalam berkarya. Einstein memberikan materi menggambar dengan kecanggihan produk Faber-Castell sehingga menghasilkan karya yang bagus, serta kebijaksanaan Einstein dalam berkarya untuk mengingatkan audience agar rajin untuk berlatih menggambar dan mengajak audience untuk peduli lingkungan.

\section{Saran}

Semiotik di VCD pembelajaran menggambar Faber-Castell Seri 1 sudah baik dan berpengaruh terhadap materi pembelajaran untuk meningkatkan kualitas gambar anak-anak. Tetapi, kualitasnya didukung dengan produk Faber-Castell yang aman bagi anak-anak, lingkungan, dan menghasilkan warna cerah.

Orang tua sebaiknya menemani anaknya pada saat melihat tampilan VCD ini, karena untuk menjelaskan apa saja maksud pesan dari Einstein Kristiansen dan Faber-Castell. Hal ini dikhawatirkan banyak makna konotasi yang dapat membingungkan pikiran anak-anak. VCD pembelajaran lebih baik dilihat oleh orang tua beserta anak-anak mereka ketika belajar bersama agar terjalin hubungan yang akrab.

Penelitian ilmu semiotika sebaiknya berkelanjutan demi kemajuan media pembelajaran dan ilmu pengetahuan di Indonesia.

\section{DAFTAR PUSTAKA}

Fiske, John. 2007. Cultural and Communication Studies: Sebuah Pengantar Paling Komprehensif. Yogyakarta: Jalasutra. 
Karso, Olih Solihat. 2008. "Strukturalisme dan Semiotik". Warna: Seni Rupa dalam Multidimensi, Volume 02, No. 1 (hlm. 103).

Piliang, Y. A. 2003. Hipersemiotika: Tafsir Cultural Studies Atas Matinya Makna. Yogyakarta: Jalasutra.

Sobur, Alex. 2006. Semiotika Komunikasi. Bandung: PT. Remaja Rosdakarya.

Stokes, Jane. 2006. How to Do Media and Cultural Studies: Panduan untuk Melaksanakan Penelitian dalam
Kajian Media dan Budaya. Yogyakarta: Bentang.

Suandi, I Wayan. 2010. "Kartun dalam Perspektif Bentuk, Fungsi dan Makna pada Majalah Bog-Bog Bali Cartoon". Rupa: Jurnal Ilmiah Seni Rupa, Volume 9, No. 1 (hlm.1).

Tinarbuko, Sumbo. 2008. Semiotika Komunikasi Visual: Metode Analisis Tanda dan Makna pada Karya Desain Komunikasi Visual. Yogyakarta: Jalasutra. 